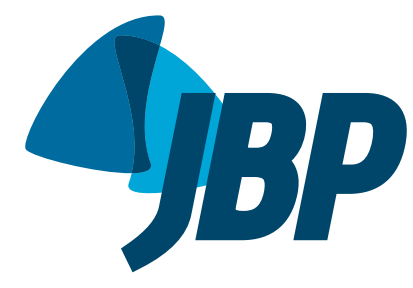

1. Programa de Pós-Graduação em Fisioterapia, Universidade do Estado de Santa Catarina - UDESC Florianópolis (SC) Brasil.

2. Núcleo de Assistência, Ensino e Pesquisa em Reabilitação Pulmonar, Universidade do Estado de Santa Catarina - UDESC Florianópolis (SC) Brasil.

3. Programa de Pós-Graduação em Ciências do Movimento Humano, Universidade do Estado de Santa Catarina - UDESC Florianópolis (SC) Brasil.

a. (ID) http://orcid.org/0000-0003-4620-9064

b. (iD) http://orcid.org/0000-0003-2082-2194

c. (iD http://orcid.org/0000-0001-6184-9495

d. (iD http://orcid.org/0000-0003-3992-924X

e. (iD http://orcid.org/0000-0003-0320-4810

Submitted: 30 April 2017

Accepted: 15 December 2017

Study carried out at the Núcleo de Assistência, Ensino e Pesquisa em Reabilitação Pulmonar, Universidade do Estado de Santa Catarina - UDESC Florianópolis (SC) Brasil.

\section{Validation of a bioelectrical impedance analysis system for body composition assessment in patients with COPD}

\author{
Fernanda Rodrigues Fonseca, ${ }^{1,2, a}$, Manuela Karloh', ${ }^{2,3, b}$, Cintia Laura Pereira de Araujo 1,2,c, \\ Cardine Martins dos Reis ${ }^{1,2, d}$, Anamaria Fleig Mayer ${ }^{1,2,3, e}$
}

\begin{abstract}
Objective: To investigate the validity of an eight-contact electrode bioelectrical impedance analysis (BIA) system within a household scale for assessing whole body composition in COPD patients. Methods: Seventeen patients with COPD (mean age = $67 \pm 8$ years; mean $\mathrm{FEV}_{1}=38.6 \pm 16.1 \%$ of predicted; and mean body mass index $=24.7$ $\pm 5.4 \mathrm{~kg} / \mathrm{m}^{2}$ ) underwent dual-energy X-ray absorptiometry (DEXA) and an eight-contact electrode BIA system for body composition assessment. Results: There was a strong inter-method correlation for fat mass ( $r=0.95)$, fat-free mass $(r=0.93)$, and lean mass ( $r$ $=0.93)$, but the correlation was moderate for bone mineral content $(r=0.73 ; p<0.01$ for all). In the agreement analysis, the values between DEXA and the BIA system differed by only $0.15 \mathrm{~kg}(-6.39$ to $6.70 \mathrm{~kg}), 0.26 \mathrm{~kg}(-5.96$ to $6.49 \mathrm{~kg}),-0.13 \mathrm{~kg}(-0.76$ to $0.50 \mathrm{~kg})$, and $-0.55 \mathrm{~kg}(-6.71$ to $5.61 \mathrm{~kg})$ for fat-free mass, lean mass, bone mineral content, and fat mass, respectively. Conclusions: The eight-contact electrode BIA system showed to be a valid tool in the assessment of whole body composition in our sample of patients with COPD.

Keywords: Pulmonary disease, chronic obstructive; Body composition; Electric impedance.
\end{abstract}

\section{INTRODUCTION}

Weight loss and depletion of muscle mass are common systemic manifestations in $\mathrm{COPD}^{(1)}$ and have been associated with the disease prognosis. It is known that body mass index (BMI) is related to the number of hospitalizations ${ }^{(2)}$ and length of hospital stay ${ }^{(3)}$ for acute exacerbation in patients with COPD, with an impact on mortality. ${ }^{(4,5)}$ The fat-free mass (FFM) index, however, seems to be a stronger predictor of mortality ${ }^{(6)}$ and disease severity $^{(7)}$ than does BMI in those patients, justifying the routine assessment of their body composition.

The use of dual-energy X-ray absorptiometry (DEXA) is recommended to assess body composition in COPD patients. ${ }^{(8,9)}$ This system distinguishes the body composition in three compartments by a difference in the attenuation of X-rays among body tissues. In comparison with DEXA, conventional bioelectrical impedance analysis (BIA) system, with four adhesive gel electrodes, has satisfactory clinical accuracy in estimating body composition in patients with COPD. ${ }^{(10)}$
The BIA system, which is based on differential opposition to the electrical current among body tissues, has been used to assess body composition in COPD patients in various studies. ${ }^{(11-13)}$

The measurement of lean mass (LM) by an eight-contact electrode BIA system has already been validated against DEXA in people ranging in age from 6 to 64 years. ${ }^{(14)}$ Additionally, this simple, practical, and convenient system was used in an epidemiological study in which FFM and FFM index were determined in men and women of white ethnicity ranging from 45 to 69 years of age. ${ }^{(15)}$ However, to the best of our knowledge, the assessment of body composition using this system has yet to be studied in patients with COPD. In those patients, factors other than age contribute to muscle atrophy, such as disuse, inflammation, oxidative stress, hypoxemia, hypercapnia, low levels of anabolic hormones or growth factors, impaired energy balance, corticosteroid use, and vitamin D deficiency. ${ }^{(16)}$ Thereby, the objective of the present study was to investigate the validity of an eight-contact

Correspondence to:

Anamaria Fleig Mayer. Núcleo de Assistência, Ensino e Pesquisa em Reabilitação Pulmonar, Universidade do Estado de Santa Catarina, Rua Paschoal Simone, 358, CEP 88080-350, Florianópolis, SC, Brasil.

Tel.: 5548 3664-8608.E-mail: anamaria.mayer@udesc.br

Financial support: This study received financial support from the Fundação de Amparo à Pesquisa do Estado de Santa Catarina/Brazilian Conselho Nacional de Desenvo/vimento Cientifico e Tecnológico (FAPESC/CNPq, Foundation for the Support of Research in the State of Santa Catarina/National Council for Scientific and Technological Development; Grant no. 3509/2010-2). 
electrode BIA system within a household scale for assessing whole body composition in COPD patients, using DEXA as the standard method.

\section{METHODS}

This was a cross-sectional study conducted between July and December of 2011. The study sample was selected by convenience and included COPD patients classified as the Global Initiative for Chronic Obstructive Lung Disease (GOLD) stages 2, 3, or 4 (presence of a post-bronchodilator $\mathrm{FEV}_{1} / \mathrm{FVC}$ ratio $<0.70$ and $\mathrm{FEV}_{1}$ $<80 \%$ of the predicted value), ${ }^{(17)}$ of both genders, who had a smoking history $\geq 20$ pack-years, had been clinically stable four weeks prior to study entry, and were $\geq 40$ years of age. Exclusion criteria were current smoking and presence of associated diseases, such as cardiomyopathy, musculoskeletal diseases, cancer, tuberculosis, or asthma. A total of 17 clinically stable COPD patients (14 men) from public or private pulmonary outpatient clinics agreed to participate in the study. The study was approved by the Research Ethics Committees of the Universidade do Estado de Santa Catarina and the Universidade Federal de Santa Catarina (Protocol numbers 85/2010 and 865.2010, respectively). All participants gave written informed consent.

\section{Pulmonary function}

Lung function was assessed using a previously calibrated spirometer (EasyOne ${ }^{\circledR}$; ndd Medical Technologies, Zurich, Switzerland). Spirometry was performed before and after the inhalation of $400 \mu \mathrm{g}$ of albuterol in accordance with the American Thoracic Society/European Respiratory Society standards. ${ }^{(18)}$ The predicted values were calculated based on equations proposed by Pereira et al.(19)

\section{Nutritional status}

During the assessment of nutritional status, the individuals remained barefoot and unadorned, wearing only an apron. Height was measured with a wall-mounted stadiometer (Standard; Sanny, São Bernardo do Campo, Brazil) in accordance with the standardization proposed by Gordon et al. ${ }^{(20)}$ Weight and body composition variables were measured with a household segmental body composition monitor (BC558 Ironman; Tanita Corp., Tokyo, Japan). That body composition monitor operates at $50 \mathrm{kHz}$ and contains eight contact electrodes, two pairs of electrodes being coupled to a metal platform for the feet and two pairs for hand grasping. The metal platform is attached to a force transducer for the measurement of weight, and the eight contact electrodes are connected to a digital circuit. The measurement of body composition variables by the eight-contact electrode BIA system was performed as per the instructions of the manufacturer and as recommended by Kyle et al. (21) Measurements were taken ten minutes after the patients had been positioned in orthostatic position, in order to minimize errors caused by acute changes in body fluid distribution. (22) Data on total body composition-body fat percentage, muscle mass, and bone mass-were collected.

On the same day, body composition was also assessed by whole-body DEXA scanning, which was conducted by a medical radiology technician certified by the Brazilian Society of Clinical Densitometry. The subjects laid still in the supine position during the evaluation. A Lunar Prodigy Advance bone densitometer (GE Healthcare, Madison, WI, USA) was previously calibrated in accordance with the manufacturer's recommendations and used with the enCORE software, version 12.30 (GE Healthcare) for the acquisition of the following body composition variables: bone mineral content (BMC); LM, fat mass (FM); and FFM (in kg for all). For the inter-method analysis, the following was considered: $\mathrm{FM}=$ (total body weight $\times \mathrm{FM} \%$ ) $/ 100 ; \mathrm{FFM}=$ total body weight $-\mathrm{FM}$; $\mathrm{LM}=$ muscle mass; and $\mathrm{BMC}=$ bone mass.

\section{Statistical analysis}

The data were reported as means \pm SD. The ShapiroWilk test was used to analyze data normality. A paired t-test was used in order to compare the means of the body composition variables obtained via BIA and DEXA. Pearson's correlation coefficient was used in order to test the association between the variables obtained by the two assessment methods, whereas Bland \& Altman scatter plots were used to assess agreement between the methods. Statistical significance was set at $p<$ 0.05 . All statistical analyses were performed with the IBM SPSS Statistics software package, version 20.0 (IBM Corporation, Armonk, NY, USA).

\section{RESULTS}

The sample comprised 17 subjects (14 men) classified as GOLD stage 2 (moderate COPD; $n=4$ ), 3 (severe COPD; $n=6$ ), and 4 (very severe COPD; $n=7)$. Regarding medications, $14(80 \%)$ of the subjects reported the use of long-acting $\beta_{2}$ agonists combined with corticosteroids; $11(67 \%)$ used longacting anticholinergics; 9 (53\%) used long-acting $\beta_{2}$ agonists; 3 (20\%) used short-acting $\beta_{2}$ agonists combined with anticholinergics; and 1 (7\%) used short-acting xanthines. The characteristics of the sample are shown in Table 1.

There were no significant differences between body composition variables obtained by DEXA and by BIA (Table 2), both correlating positively. The variables measured by BIA (FFM, LM, and FM) showed strong correlations with the respective variables measured by DEXA, whereas the BMC values showed a moderate correlation between the methods (Figure 1).

Figure 2 shows the agreement between body composition variables measured by DEXA and by BIA. The inter-method differences (IMDs) and the limits of agreement (LOA) for FFM, LM, BMC, and FM values were $0.15 \mathrm{~kg}(-6.39$ to $6.70 \mathrm{~kg}), 0.26 \mathrm{~kg}(-5.96$ to $6.49 \mathrm{~kg}),-0.13 \mathrm{~kg}(-0.76$ to $0.50 \mathrm{~kg})$, and $-0.55 \mathrm{~kg}$ 
Table 1. Characteristics of the study group.

\begin{tabular}{lcc}
\multicolumn{1}{c}{ Characteristic } & Mean \pm SD & Range \\
Age, years & $67 \pm 8$ & $56-79$ \\
Smoking history, pack-years & $50(24-74)^{\mathrm{a}}$ & $21-150$ \\
$\mathrm{FEV}_{1} / \mathrm{FVC}^{\mathrm{b}}$ & $0.45 \pm 0.11$ & $0.26-0.65$ \\
$\mathrm{FEV}_{1}, \mathrm{~L}^{\mathrm{b}}$ & $1.17 \pm 0.48$ & $0.54-2.04$ \\
$\mathrm{FEV}_{1}, \%$ predicted $^{\mathrm{b}}$ & $38.6 \pm 16.1$ & $15-65$ \\
$\mathrm{FVC}^{\mathrm{b}}, \mathrm{L}^{\mathrm{b}}$ & $2.53 \pm 0.61$ & $1.51-3.49$ \\
FVC, \% predicted $^{\mathrm{b}}$ & $64.5 \pm 16.0$ & $42-103$ \\
BMI, kg/m & $24.7 \pm 5.4$ & $16.9-33.9$ \\
\hline
\end{tabular}

BMI: body mass index. ${ }^{a}$ Value expressed as median

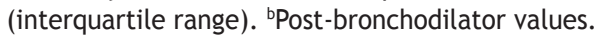

( -6.71 to $5.61 \mathrm{~kg})$, respectively. The body composition variables were within the LOA, except for the BMC value of one patient.

\section{DISCUSSION}

The aim of the present study was to investigate the validity of an eight-contact electrode BIA system for the assessment of total body composition in a sample of patients with moderate to very severe COPD, using DEXA as the standard evaluation method. Measurements of FFM, LM, and FM obtained by the two methods showed strong positive correlations. In

Table 2. Body composition of the study group.

\begin{tabular}{lccccc}
\multicolumn{2}{c}{ Variable } & \multicolumn{2}{c}{ DEXA } & BIA & M \\
& Mean \pm SD & Range & Mean \pm SD & Range & 0.848 \\
FFM, kg & $50.7 \pm 8.5$ & $35.1-64.3$ & $50.6 \pm 8.6$ & $38.9-63.0$ & 0.730 \\
LM, kg & $48.3 \pm 8.2$ & $33.6-61.4$ & $48.0 \pm 8.2$ & $36.9-59.9$ & 0.107 \\
BMC, kg & $2.43 \pm 0.46$ & $1.59-3.35$ & $2.56 \pm 0.39$ & $2.00-3.10$ & 0.471 \\
FM, kg & $20.7 \pm 9.4$ & $5.06-33.9$ & $21.3 \pm 8.3$ & $9.89-35.3$ &
\end{tabular}

DEXA: dual-energy X-ray absorptiometry; BIA: bioelectrical impedance analysis; FFM: fat free mass; LM: lean mass; BMC: bone mineral content; and FM: fat mass.

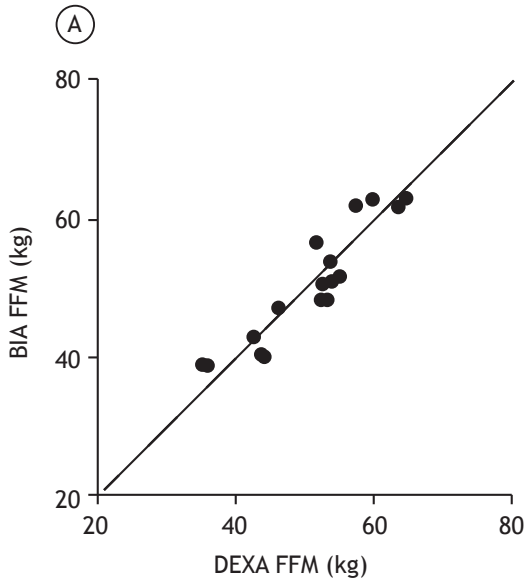

(C)

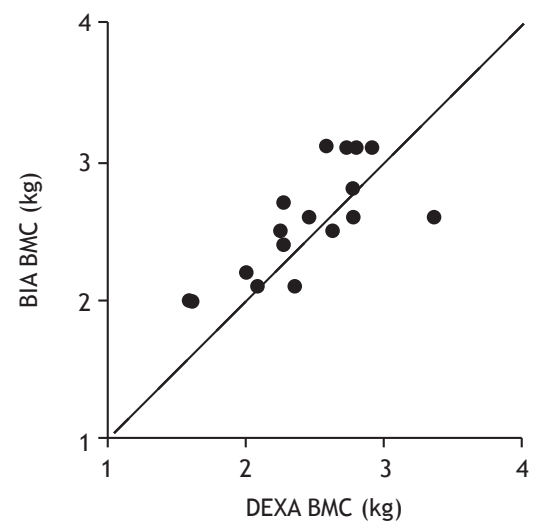

(B)

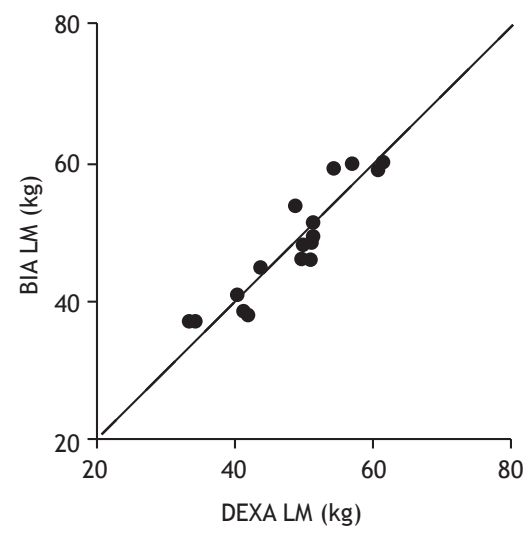

(D)

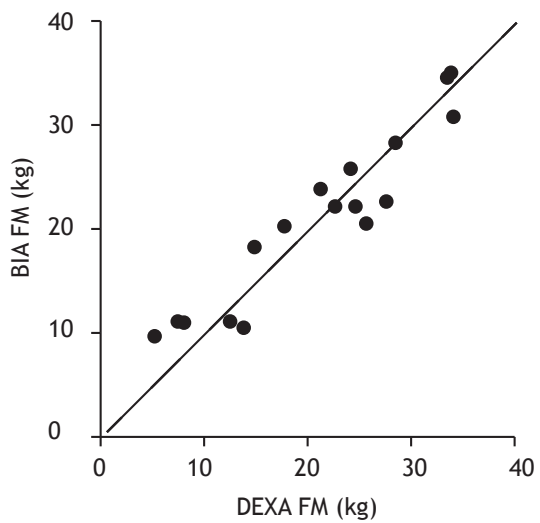

Figure 1. Correlation between body composition variables assessed by dual-energy X-ray absorptiometry and the eightcontact electrode bioelectrical impedance analysis system. DEXA: dual-energy X-ray absorptiometry; BIA: bioelectrical impedance analysis; FFM: fat free mass; LM: lean mass; BMC: bone mineral content; and FM: fat mass. 
(A)

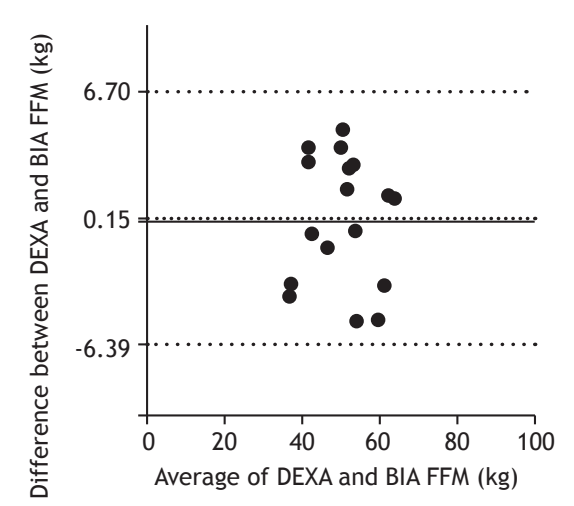

(C)

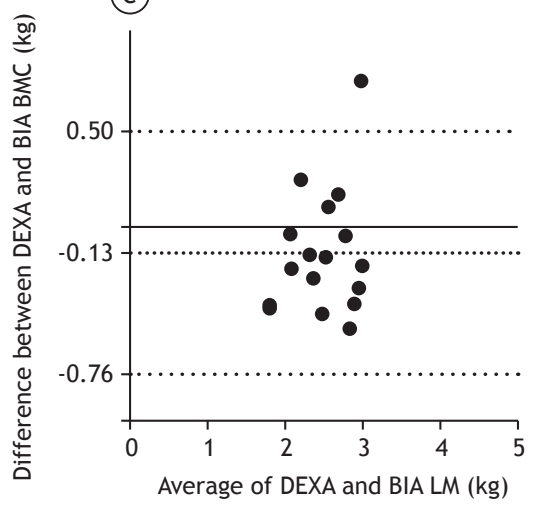

(B)

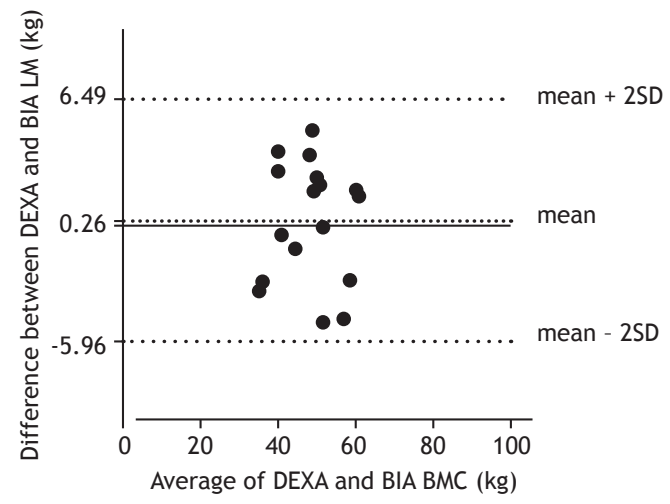

(D)

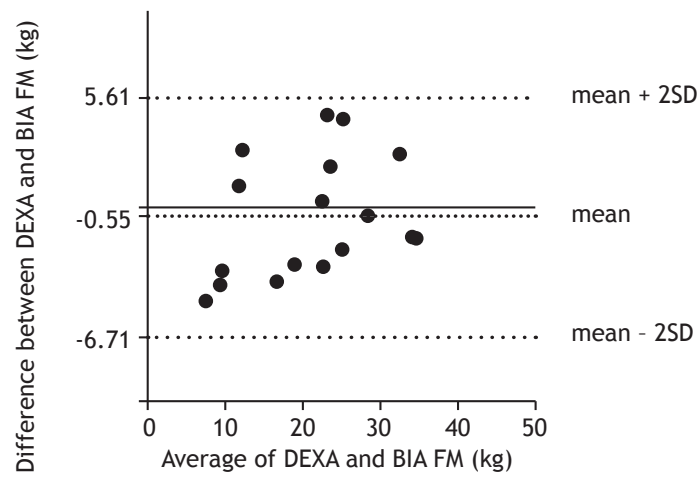

Figure 2. Mean differences and limits of agreement between body composition variables assessed by dual-energy $X$-ray absorptiometry and the eight-contact electrode bioelectrical impedance analysis system. DEXA: dual-energy X-ray absorptiometry; BIA: bioelectrical impedance analysis; FFM: fat free mass; LM: lean mass; BMC: bone mineral content; and FM: fat mass.

the agreement analysis, slight IMDs were observed between the body composition variables obtained by DEXA and the BIA system, with no statistical differences. To our knowledge, the validity of that BIA system for assessing body composition in COPD patients has never been investigated before. However, previous studies have used DEXA as the criterion method for analyzing the ability of various equations to estimate body composition by conventional BIA systems as an evaluation method for those patients. ${ }^{(10,23-26)}$

In the current study, a strong inter-method correlation was found for FFM, LM, and FM values. Lerario et al. ${ }^{(10)}$ also observed a strong correlation between FFM values measured by DEXA and by a conventional BIA system in patients with COPD $(r=0.95 ; p<0.001)$. That had been previously shown by Kyle et al. ${ }^{(24)}$ in patients with chronic respiratory failure $(r=0.952 ; p<0.0001)$. Pichard et al. ${ }^{(23)}$ studied the association between DEXA and several equations for the estimation of body composition by using a conventional BIA system in patients with chronic respiratory failure. Those authors found a minimum correlation coefficient of 0.66 ( $p<$ 0.001 ) for FFM and FM. In heavy smokers, Rom et al. ${ }^{(27)}$ showed a strong correlation between BMC $(r=$
$0.81), L M(r=0.94)$, and FM $(r=0.97)$ measured by an eight-contact electrode BIA system and DEXA).

When analyzing the agreement between the methods in the present study, we found that the eight-contact electrode BIA system slightly underestimated FFM values when compared with those by DEXA. Corroborating this result, underestimated values for FFM obtained by conventional BIA systems compared with those measured by DEXA in COPD patients were also observed in other studies. $(10,25,26)$ The bias ranged between 0.57 and $4.1 \mathrm{~kg}$, which is greater than that observed in the current study. ${ }^{(10,25,26)}$ However, FFM values were overestimated by BIA when compared with DEXA in other studies involving patients with chronic respiratory failure, with biases between 0.1 and $8.0 \mathrm{~kg}$. 23,24$)$

In the present study, the eight-contact electrode BIA system underestimated LM when it was compared with DEXA. It is known that FFM is primarily composed by LM, and, therefore, when there is FFM underestimation, LM underestimation is also expected. Overestimated FM values were obtained by the eight-contact electrode BIA system when they were compared with those by DEXA. However, Rom et al.(27) found underestimated FM values obtained by an eight-contact electrode 
BIA system when compared with those obtained by DEXA (IMDs $=0.19 \mathrm{~kg}$ ) in heavy smokers. In healthy elderly Europeans, Mally et al.(28) found that an eight-contact electrode BIA system underestimated LM $($ IMDs $=1.0 \mathrm{~kg})$ and overestimated FM (IMDs = $-5.8 \mathrm{~kg}$ ) when compared with the values obtained by DEXA in men, which confirms the results observed in the current study, since our sample was composed mostly by males. In the present study, we also found that the eight-contact electrode BIA system slightly overestimated $B M C$ values when compared with those by DEXA and that the BMC values measured by the two methods showed a moderate correlation. BMC is a component of FFM, and it appears to be decreased in COPD patients. ${ }^{(29)}$ It is known that DEXA enables the identification of bone mineral loss in these patients ${ }^{(8)}$ and is considered the gold standard for bone mass determination. This suggests that the eight-contact electrode BIA system is not as accurate a method as DEXA for the evaluation of the skeletal status of patients with COPD.

Although DEXA is not considered the gold standard for body composition evaluation,(30) it has been recommended as a reference method for this purpose in COPD patients. ${ }^{(8,9)}$ Its high cost and demand on training and technological resources, however, limit its use in clinical practice. Because BIA has lower costs and is easy to use, it has been chosen as a method for assessing body composition in patients with COPD in some studies. ${ }^{(11,12)}$ The eight-contact electrode BIA system associated with household scales dispenses with the use of adhesive gel electrodes, has lower costs than does a conventional BIA monitor, and enables easy and immediate assessment of body composition and weight. We found that the eight-contact electrode BIA system, in addition to its simplicity, practicality, and convenience, can be used as an alternative to more complex methods for routine assessment of body composition in patients with COPD in clinical practice and epidemiological studies.

The exclusion of patients with mild airflow obstruction in our sample can be identified as a limiting factor, making the extrapolation of the observed results not possible for those patients. Moreover, the small sample size, recruited by convenience from public and private pulmonary clinics, reduces the external validity of the study because the sample might not be representative of the general COPD population in terms of body composition. In addition, the analysis of groups according to the severity of airflow obstruction, gender, or nutritional status cannot be made in our study. Despite the small sample size, the statistical power for all correlations observed between the body composition variables obtained by DEXA and by the eight-contact electrode BIA system was greater than $90 \%$. Further investigations using a larger and randomly selected sample of patients with COPD are recommended in order to confirm our results. Another limitation that could be pointed out is that the responsiveness of the BIA system to an intervention was not evaluated because of the cross-sectional design of the present study.

In conclusion, the eight-contact electrode BIA system is a simple and useful tool for the assessment of whole body composition in clinically stable patients with moderate to very severe COPD, and the difference in LOA does not seem to have an impact on the validity of the method.

\section{ACKNOWLEDGMENTS}

We would like to thank Leila Marques John Steidle, Pablo Moritz, Tatjana Almeida Prado, Camilo Fernandes, and Fatima Almeida Saitn Martin (pulmonologists) for referring their patients to our study. We would also like to thank Ivo Sebastian Garzel Junior (radiologist) and Sonitec ${ }^{\circledR}$ clinic of medical diagnostic imaging for performing the DEXA scans.

\section{REFERENCES}

1. Choudhury G, Rabinovich R, MacNee W. Comorbidities and systemic effects of chronic obstructive pulmonary disease. Clin Chest Med. 2014;35(1):101-30. https://doi.org/10.1016/j.ccm.2013.10.007

2. Hallin R, Koivisto-Hursti UK, Lindberg E, Janson C. Nutritional status, dietary energy intake and the risk of exacerbations in patients with chronic obstructive pulmonary disease (COPD). Respir Med. 2006;100(3):561-7. https://doi.org/10.1016/j.rmed.2005.05.020

3. Gupta B, Kant S, Mishra R, Verma S. Nutritional status of chronic obstructive pulmonary disease patients admitted in hospital with acute exacerbation. J Clin Med Res. 2010;2(2):68-74. https://doi. org/10.4021/jocmr2010.03.261e

4. Cao C, Wang R, Wang J, Bunjhoo $H, X u$ Y, Xiong W. Body mass index and mortality in chronic obstructive pulmonary disease: a meta-analysis. PloS One. 2012;7(8):e43892. https://doi.org/10.1371/ journal.pone.0043892

5. Guo Y, Zhang T, Wang Z, Yu F, Xu Q, Guo W, et al. Body mass index and mortality in chronic obstructive pulmonary disease: A doseresponse meta-analysis. Medicine (Baltimore). 2016;95(28):e4225. https://doi.org/10.1097/MD.0000000000004225

6. Schols AM, Broekhuizen R, Weling-Scheepers CA, Wouters EF Body composition and mortality in chronic obstructive pulmonary disease. The Am J Clin Nutr. 2005;82(1):53-9. https://doi.org/10.1093/ ajcn/82.1.53

7. Ischaki E, Papatheodorou G, Gaki E, Papa I, Koulouris N, Loukides S Body mass and fat-free mass indices in COPD: relation with variables expressing disease severity. Chest. 2007;132(1):164-9. https://doi. org/10.1378/chest.06-2789

8. Engelen MP, Schols AM, Heidendal GA, Wouters EF. Dual-energy X-ray absorptiometry in the clinical evaluation of body composition and bone mineral density in patients with chronic obstructive pulmonary disease. Am J Clin Nutr. 1998;68(6):1298-303. https://doi. org/10.1093/ajcn/68.6.1298

9. Miller A, Strauss BJ, Mol S, Kyoong A, Holmes PH, Finlay P, et al. Dual-energy $X$-ray absorptiometry is the method of choice to assess body composition in COPD. Respirology. 2009;14(3):411-8. https:// doi.org/10.1111/j.1440-1843.2009.01499.x

10. Lerario MC, Sachs A, Lazaretti-Castro M, Saraiva LG, Jardim JR. Body composition in patients with chronic obstructive pulmonary disease: which method to use in clinical practice? Br J Nutr. 2006;96(1):86-92. https://doi.org/10.1079/BJN20061798

11. Schols AM, Soeters PB, Dingemans AM, Mostert R, Frantzen PJ, Wouters EF. Prevalence and characteristics of nutritional depletion in patients with stable COPD eligible for pulmonary rehabilitation. $\mathrm{Br} J$ Nutr. 2006;96(1):86-92

12. Vermeeren MA, Creutzberg EC, Schols AM, Postma DS, Pieters WR, Roldaan $A C$, et al. Prevalence of nutritional depletion in a 
large out-patient population of patients with COPD. Respir Med. 2006;100(8):1349-55. https://doi.org/10.1016/j.rmed.2005.11.023

13. Humphreys K, Cross G, Frith P, Cafarella P. Nutritional status and dietary intake of outpatients with chronic obstructive pulmonary disease. Nutr Diet. 2008;65(2):168-74. https://doi.org/10.1111/j.1747 0080.2008.00235.x

14. Pietrobelli A, Rubiano F, St-Onge MP, Heymsfield SB. New bioimpedance analysis system: improved phenotyping with wholebody analysis. Eur J Clin Nutr. 2004;58(11):1479-84. https://doi. org/10.1038/sj.ejcn.1601993

15. Franssen FM, Rutten EP, Groenen MT, Vanfleteren LE, Wouters EF, Spruit MA. New reference values for body composition by bioelectrical impedance analysis in the general population: results from the UK Biobank. J Am Med Dir Assoc. 2014;15(6):448.e1-6. https://doi.org/10.1016/j.jamda.2014.03.012

16. Maltais F, Decramer M, Casaburi R, Barreiro E, Burelle $Y$, Debigaré $R$, et al. An official American Thoracic Society/European Respiratory Society statement: update on limb muscle dysfunction in chronic obstructive pulmonary disease. Am J Respir Crit Care Med. 2014;189(9):e15-62 https://doi.org/10.1164/rccm.201402-0373ST

17. Global Initiative for Chronic Obstructive Lung Disease (GOLD) [homepage on the Internet]. Bethesda: GOLD [cited 2017 Apr 1] GOLD 2017 Global Strategy for the Diagnosis, Management and Prevention of COPD. Available from: http://www.goldcopd.org/.

18. Miller MR, Hankinson J, Brusasco V, Burgos F, Casaburi R, Coates A et al. Standardisation of spirometry. Eur Respir J. 2005;26(2):319-38. https://doi.org/10.1183/09031936.05.00034805

19. Pereira CA, Sato T, Rodrigues SC. New reference values for forced spirometry in white adults in Brazil. J Bras Pneumol. 2007:33(4):397 406. https://doi.org/10.1590/S1806-37132007000400008

20. Gordon CW, Roche AF. Stature, recumbent length, weight. In Lohman TG, Roche AF, Martorell R. Anthropometric standardizing reference manual. Champaign, IL: Human Kinetics Books; 1988

21. Kyle UG, Bosaeus I, De Lorenzo AD, Deurenberg P, Elia M, Manue Gómez J, et al. Bioelectrical impedance analysis-part II: utilization in clinical practice. Clin Nutr. 2004;23(6):1430-53. https://doi. org/10.1016/j.clnu.2004.09.012

22. Jebb SA, Cole TJ, Doman D, Murgatroyd PR, Prentice AM. Evaluation of the novel Tanita body-fat analyser to measure body composition by comparison with a four-compartment model. $\mathrm{Br} J$ Nutr. 2000;83(2):115-22. https://doi.org/10.1017/S0007114500000155

23. Pichard C, Kyle UG, Janssens JP, Burdet L, Rochat T, Slosman DO, et al. Body composition by X-ray absorptiometry and bioelectrical impedance in chronic respiratory insufficiency patients. Nutrition. 1997;13(11-12):952-8. https://doi.org/10.1016/S0899 9007(97)00336-5

24. Kyle UG, Pichard C, Rochat T, Slosman DO, Fitting JW, Thiebaud $D$. New bioelectrical impedance formula for patients with respiratory insufficiency: comparison to dual-energy X-ray absorptiometry. Eur Respir J. 1998;12(4):960-6. https://doi.org/10.1183/09031936.98.12 040960

25. Steiner MC, Barton RL, Singh SJ, Morgan MD. Bedside methods versus dual energy $\mathrm{X}$-ray absorptiometry for body composition measurement in COPD. Eur Respir J. 2002;19(4):626-31. https://doi. org/10.1183/09031936.02.00279602

26. Rutten EP, Spruit MA, Wouters EF. Critical view on diagnosing muscle wasting by single-frequency bio-electrical impedance in COPD. Respir Med. 2010;104(1):91-8. https://doi.org/10.1016/j. rmed.2009.07.004

27. Rom O, Reznick AZ, Keidar Z, Karkabi K, Aizenbud D. Body composition in heavy smokers: comparison of segmental bioelectrical impedance analysis and dual-energy X-ray absorptiometry. Adv Exp Med Biol. 2015;840:1-11.

28. Mally K, Trentmann J, Heller M, Dittmar M. Reliability and accuracy of segmental bioelectrical impedance analysis for assessing muscle and fat mass in older Europeans: a comparison with dual-energy X-ray absorptiometry. Eur J Appl Physiol. 2011;111(8):1879-87. https://doi.org/10.1007/s00421-010-1795-X

29. Engelen MP, Schols AM, Lamers RJ, Wouters EF. Different patterns of chronic tissue wasting among patients with chronic obstructive pulmonary disease. Clin Nutr. 1999;18(5):275-80. https://doi org/10.1016/S0261-5614(98)80024-1

30. Genton L, Hans D, Kyle UG, Pichard C. Dual-energy X-ray absorptiometry and body composition: differences between devices and comparison with reference methods. Nutrition. 2002;18(1):6670. https://doi.org/10.1016/S0899-9007(01)00700-6 